\title{
Appropriateness of pediatric CT utilization in clinical practice
}

\author{
Panruethai Trinavarat, M.D. ${ }^{(1)}$ \\ Nisanard Pisuchpen, M.D. ${ }^{(1)}$ \\ Sasitorn Petcharunpaisan, M.D. ${ }^{(1)}$ \\ Darintr Sosothikul, M.D. ${ }^{(2)}$ \\ Jitladda Deerojanawong, M.D. ${ }^{(2)}$ \\ Montida Veeravigrom, M.D. ${ }^{(2)}$ \\ Jiraporn Amornfa, M.D. ${ }^{(3)}$ \\ Paisarn Vejchapipat, M.D. ${ }^{(3)}$
}

Michael Riccabona, M.D. ${ }^{(4)}$

From The ${ }^{(1)}$ Department of Radiology, ${ }^{(2)}$ Department of Pediatrics, ${ }^{(3)}$ Department of Surgery, Faculty of Medicine, Chulalongkorn University, Bangkok, Thailand

(4) Division of Paediatric Radiology, Department of Radiology,

University Hospital LKH Graz, Graz, Austria

Address correspondence to P.T. (e-mail: pantrinavarat@hotmail.com)

\section{Abstract}

Background: Justification of imaging investigations is important, particularly in pediatrics which underwent investigation using a relatively higher radiation such as $\mathrm{CT}$, due to the higher radiation sensitivity in children.

Objective: To assess the difference of viewpoints between pediatric physicians and pediatric radiologists on the appropriateness of pediatric CT utilization in a tertiary-care university hospital with limited MR capacity. 
Methods: Pediatric medical records of head CT, chest CT, and abdominal CT were retrospectively reviewed in consecutive date of the examination until having 100 head CTs and 100 body CTs with complete clinical and imaging information. The physicians and the radiologists were asked to suggest the imaging modality of choice for each patient according to the given data, regardless of the hospital's limitation. If the suggested modality of choice was not CT, the CT request would be considered as "inappropriate". They additionally scored the CT appropriateness, firstly using individual judgment, and secondly using the American College of Radiology Appropriateness Criteria (ACR AC). Both scoring methods used the same rating scale from 1 to 9; scores 1-3 were considered "inappropriate".

Results: From the viewpoint of the physicians and radiologists, the number of inappropriate CT requests was $20 \%$ and $54 \%$ according to "the modality of choice", $2.5 \%$ and $17 \%$ according to "individual judgment", $12 \%$ and $22 \%$ according to the ACR AC. The main difference was not from no indication for imaging but from the selected modality of imaging. The radiologists suggested $52 \%$ of head CTs and $64 \%$ of abdominal CTs could have been replaced by MRI if available.

Conclusion: There is a ten-percent disagreement on appropriateness of pediatric $\mathrm{CT}$ request between the physicians and the radiologists when using the same guidelines and considering the hospital limitations.

Key words: ACR appropriateness criteria, appropriateness, computed tomography, justification, pediatrics

\section{Introduction}

Exposure to ionizing radiation, including X-ray, increases the risk of developing of fatal cancer in the future with a much higher risk in pediatrics than adults [1-5]. CT is one of the major concerns because it gives a relatively higher radiation dose in diagnostic imaging; additionally, there has been a continuous increase of CT examinations in many countries [6-10]. Adjusted to the 1997 European Commission's directive, CT should be performed only when a patient's 
benefit is foreseen and no other available imaging modalities without or with a lower radiation dose could provide the same information [11]. In the United States, there is the ACR Appropriateness Criteria (ACR AC) as a guideline for indicating imaging investigation which includes radiation concerns as a part of appropriateness [12]. For the countries with limited resources such as in South East Asian countries, there is a significant challenge in providing MRI with enough capacity.

The number of unnecessary imaging incidents was estimated at $10 \%-30 \%$ [13], and the number of inappropriate CT examinations was reported at 27\% - 30\% [14$15]$.

In this article, the appropriateness of CT request in pediatrics was studied from the viewpoints of the referring physicians and the radiologists in a tertiary-care hospital with limited MRI capacity.

\section{Materials and methods}

The authors' institution review board approved the study protocol. The informed consent was waived and the patient confidentiality was protected.

Medical records of pediatric patients under 15 years old having head CT, chest CT, and abdominal CT in a single institution since January 1st, 2012 were retrospectively reviewed in consecutive date of the examination until having 100 head CTs and 100 body CTs with complete clinical and imaging information. The review was done in 2014. The exclusion criteria were insufficient clinical information for evaluation of justification of a CT examination. PET-CT and CT scanning as a part of treatment purpose, such as CT for guiding intervention, CT navigation for operation, and CT simulation for radiation therapy were excluded.

CT examinations were done in a single hospital. It was a 1325-bed, tertiary-care university hospital for both adult and pediatric patients. There were 170 beds for pediatric in-patients and approximately 57,000 pediatric OPD viits per 
year. In the year 2012, there were $2 \mathrm{MR}$ machines and $3 \mathrm{CT}$ scanners (Somatom Sensation 4 and Somatom Sensation 16, both from Siemens Healthcare, Erlangen, Germany; and Aquilion One, Toshiba Medical Systems, Otawara, Japan).

Patients' history of illnesses, physical examinations, laboratory results, prior imaging results, responses to prior treatments, and reasons for CT requests were retrospectively reviewed.

The appropriateness of CT requests was assessed by both physicians and radiologists (a neuroradiologist with four years of experience and a pediatric body radiologist with fifteen-years of experience) who worked in pediatric subspecialties, including neurology, neurosurgery, neuroradiology, pulmonology, oncology, general surgery, and body imaging.

Each CT request would be assessed by one physician and one radiologist according to his or her subspecialty. They were asked to suggest the most appropriate imaging modality for each patient without consideration of hospital limitations. If the suggested modality was not CT and would deliver less or no radiation, the CT request would be considered "inappropriate" according to the "imaging modality of choice" criteria.

The specialists were then asked to score the appropriateness for each CT request by using their individual judgment in their usual environments, and then by using the ACR AC 2012 [12] for the cases who matched the specific clinical conditions of the criteria. Both scoring methods used the same ordinal scale from one to nine: scores 1-3 for "inappropriate", scores 4-6 for "may be appropriate", and scores 7-9 for "appropriate".

The considered inappropriateness of a CT request by the physicians and the radiologists, respectively, using the three different criteria - (a) CT not the modality of choice, (b) scores 1-3 from individual judgment, and (c) scores 1-3 from the ACR AC - were compared and analyzed. 
In terms of the statistical analysis, demographic data of the patients were shown as mean $( \pm \mathrm{SD})$ and percentage. The appropriateness of the CT examination was presented as mean $( \pm \mathrm{SD})$ score and percentage of each categorized group. The difference between ACR rating score and appropriateness rating score was calculated by pair t-test. Statistical significance was defined as p-value less than 0.05. Cohen's kappa coefficient analysis and Spearman rank correlation coefficient were used for measurement of the inter-rater agreement and the correlation between pediatric radiologists and pediatric specialists, respectively. All statistical analyses were computed using SPSS version 20.

\section{Results}

Two-hundred CT examinations in 136 patients (67 boys and 69 girls) were enrolled. The patients' ages ranged from 1 month to 15 years with the mean age of $8.35 \pm 4.86$ years.

There were 100 head CTs and 100 body CTs (44 CT of the chest, and 56 CT of the abdomen). Indications for CT are shown in Table 1.

Table 1. Indications for CT examination according to CT areas.

\begin{tabular}{|c|c|c|c|c|c|}
\hline \multicolumn{2}{|c|}{100 head CTs } & \multicolumn{2}{|c|}{44 chest $\mathrm{CTs}$} & \multicolumn{2}{|c|}{56 abdominal CTs } \\
\hline Indication & $\%$ & Indication & $\%$ & Indication & $\%$ \\
\hline Head injury & 34 & Follow-up* & 48 & Follow-up* & 55 \\
\hline Seizure & 19 & Tumor staging & 32 & Tumor staging & 14 \\
\hline Follow-up ${ }^{*}$ & 14 & Others ${ }^{* *}$ & 20 & $\begin{array}{l}\text { "Rule out" a surgical } \\
\text { condition }\end{array}$ & 13 \\
\hline Headache & 12 & & & & \\
\hline Conscious change & 6 & & & Trauma & 9 \\
\hline Tumor staging & 5 & & & Others ${ }^{\star *}$ & 9 \\
\hline Others ** & 10 & & & & \\
\hline
\end{tabular}

* The "follow-up" CT indications were mostly for tumors after treatment.

** The others were miscellaneous other conditions such as inflammation. 
Five pediatric physicians and two pediatric radiologists evaluated CT requests according to their expertise with the distribution of the requests shown in Table 2.

Table 2. Number and area of CT requests distributing to pediatric physicians and pediatric radiologists for assessment.

\begin{tabular}{|c|c|c|c|}
\hline $\begin{array}{l}\text { Number and area } \\
\text { of CT requests }\end{array}$ & \multicolumn{2}{|c|}{$\begin{array}{l}5 \text { pediatric physicians } \\
\text { and number of CT } \\
\text { requests assessed }\end{array}$} & $\begin{array}{l}2 \text { pediatric radiologists } \\
\text { and number of CT } \\
\text { requests assessed }\end{array}$ \\
\hline 100 head CTs & $\begin{array}{l}\text { Neurosurgeon } \\
\text { Neurologist } \\
\text { Oncologist }\end{array}$ & $\begin{array}{l}44 \text { requests } \\
43 \text { requests } \\
13 \text { requests }\end{array}$ & $\begin{array}{l}\text { Neuroradiologist } \\
100 \text { requests }\end{array}$ \\
\hline 44 chest CTs & $\begin{array}{l}\text { Oncologist } \\
\text { Pulmonologist }\end{array}$ & $\begin{array}{l}32 \text { requests } \\
12 \text { requests }\end{array}$ & $\begin{array}{l}\text { Body imaging radiologist } \\
44 \text { requests }\end{array}$ \\
\hline 56 abdominal CTs & $\begin{array}{l}\text { Oncologist } \\
\text { Surgeon }\end{array}$ & $\begin{array}{l}44 \text { requests } \\
12 \text { requests }\end{array}$ & $\begin{array}{l}\text { Body imaging radiologist } \\
56 \text { requests }\end{array}$ \\
\hline
\end{tabular}

From 100 head CTs, there were 64 requests meeting the specific clinical conditions of the ACR AC, with the indications of trauma, headache, and seizure. From 100 body CTs, only 4 abdominal CTs met the clinical conditions of the ACR AC, with the indication of right lower quadrant pain.

When using the "imaging modality of choice" as the criteria for CT justification, the number of inappropriate CT utilizations in the studied hospital was $20 \%$ by the opinion of the physicians and $54 \%$ by the opinion of the radiologists. The radiologists suggested $52 \%$ of head CTs and $64 \%$ of abdominal CTs could have been replaced by MRI if available, while the physicians suggested $27 \%$ and $3 \%$, respectively. The modality of choice was plain radiograph or not necessary in $4 \%-5 \%$ of the requests.

When the "individual judgment" was used as the criteria for CT justification, the number of inappropriate CT requests (scores 1-3) was $2.5 \%$ and $17 \%$ by the 
physicians and by the radiologists, respectively. The mean score of appropriateness from the physicians and the radiologists was 7.63 and 6.28 , consecutively.

When the ACR AC was used in 68 criteria-matched cases, the number of inappropriate CT requests (scores $1-3$ ) were $12 \%$ and $22 \%$ by the physicians and by the radiologists, respectively. The mean score of appropriateness from the physicians and the radiologists was 6.57 and 5.85, respectively. The correlation of scoring and the agreement of grouping between the physicians and radiologists were strongest when using the ACR AC.

The percentage of inappropriate CT requests according to each criterion assessed by the physicians and the radiologists, respectively, is shown in Table 3.

Table 3. The percentage of inappropriate CT requests according to scanning areas, criteria of assessment and assessors.

\begin{tabular}{|c|c|c|c|c|c|}
\hline \multirow[t]{2}{*}{ CT area } & \multirow{2}{*}{$\begin{array}{l}\text { Number } \\
\text { Assessor }\end{array}$} & \multicolumn{4}{|c|}{ Criteria for assessment } \\
\hline & & $\begin{array}{l}\text { Modality } \\
\text { of choice }\end{array}$ & $\begin{array}{l}\text { Individual } \\
\text { judgment }\end{array}$ & $\begin{array}{l}\text { Individual } \\
\text { judgment* }\end{array}$ & ACR AC \\
\hline \multirow[t]{3}{*}{ Brain } & Number & 100 & 100 & 64 & 64 \\
\hline & Physician & $33 \%$ & $5 \%$ & $6 \%$ & $12 \%$ \\
\hline & Radiologist & $53 \%$ & $27 \%$ & $23 \%$ & $23 \%$ \\
\hline \multirow[t]{3}{*}{ Chest } & Number & 44 & 44 & - & - \\
\hline & Physician & W0\% & $0 \%$ & & \\
\hline & Radiologist & $30 \%$ & $11 \%$ & & \\
\hline \multirow[t]{3}{*}{ Abdomen } & Number & 56 & 56 & 4 & 4 \\
\hline & Physician & $11 \%$ & $0 \%$ & $0 \%$ & $0 \%$ \\
\hline & Radiologist & $75 \%$ & $3.5 \%$ & $0 \%$ & $0 \%$ \\
\hline \multirow[t]{3}{*}{ Total } & Number & 200 & 200 & 68 & 68 \\
\hline & Physician & $20 \%$ & $2.5 \%$ & $6 \%$ & $12 \%$ \\
\hline & Radiologist & $54 \%$ & $17 \%$ & $22 \%$ & $22 \%$ \\
\hline
\end{tabular}

Individual judgment ${ }^{*}$ was for the assessment of the $68 \mathrm{CT}$ requests that matched the specific clinical conditions of the ACR AC for comparison with the scores by the ACR AC. 
The scores from "individual judgment" by the physicians and the radiologists are shown in Table 4. The highest score belonged to the chest CT request, followed by the abdominal CT, and then the head CT. The physicians gave higher scores than the radiologists for all of the CT areas.

Table 4. Scores for CT requests by "individual judgment" of the physicians and the radiologists.

\begin{tabular}{|c|c|c|c|c|c|c|}
\hline CT area & Assessors & $\begin{array}{c}\text { Mean } \\
\text { score (SD) }\end{array}$ & Score 1-3 & Score 4-6 & Score 7-9 & Total \\
\hline \multirow[t]{2}{*}{ Head } & Physicians & $7.23(1.88)$ & $5(5 \%)$ & $27(27 \%)$ & $68(68 \%)$ & $100(100 \%)$ \\
\hline & Radiologist & $5.48(2.43)$ & $27(27 \%)$ & $29(29 \%)$ & $44(44 \%)$ & $100(100 \%)$ \\
\hline \multirow[t]{2}{*}{ Chest } & Physicians & $8.27(0.5)$ & 0 & 0 & $44(100 \%)$ & $44(100 \%)$ \\
\hline & Radiologist & $7.18(1.96)$ & $5(11 \%)$ & $4(9 \%)$ & $35(80 \%)$ & $44(100 \%)$ \\
\hline \multirow[t]{2}{*}{ Abdomen } & Physicians & $7.84(0.18)$ & 0 & $6(11 \%)$ & $50(89 \%)$ & $56(100 \%)$ \\
\hline & Radiologist & $7.02(0.96)$ & $2(3.5 \%)$ & $2(3.5 \%)$ & $52(93 \%)$ & $56(100 \%)$ \\
\hline
\end{tabular}

The scores of 64 head CTs that met the specific clinical conditions of the ACR $\mathrm{AC}$ are shown in Table 5. The physicians gave lower scores when using the ACR AC than when using "individual judgment" with statistical significance, while the radiologist gave the same scores.

Table 5. Scores of 64 head CT requests from "individual judgment" and from the "ACR AC" by the physicians and the radiologist.

\begin{tabular}{|c|c|c|c|c|c|c|c|}
\hline Assessors & $\begin{array}{l}\text { Scoring } \\
\text { method }\end{array}$ & $\begin{array}{l}\text { Mean score } \\
\text { (SD) }\end{array}$ & $\begin{array}{c}\text { Score } \\
1-3\end{array}$ & $\begin{array}{l}\text { Score } \\
4-6\end{array}$ & $\begin{array}{l}\text { Score } \\
7-9\end{array}$ & Total & $\begin{array}{l}\text { Scoring difference } \\
\text { by pair t-test }\end{array}$ \\
\hline Physicians & $\begin{array}{l}\text { Individual* } \\
\text { ACR AC }\end{array}$ & $\begin{array}{c}7.13(2.02) \\
6.55(2.42\end{array}$ & $\begin{array}{l}4 \\
8\end{array}$ & $\begin{array}{l}20 \\
23\end{array}$ & $\begin{array}{l}40 \\
33\end{array}$ & $\begin{array}{l}64 \\
64\end{array}$ & $\begin{array}{c}\text { Significance } \\
\mathrm{p}<0.05\end{array}$ \\
\hline Radiologist & $\begin{array}{l}\text { Individual* } \\
\text { ACR AC }\end{array}$ & $\begin{array}{l}5.78(2.56) \\
5.78(2.56)\end{array}$ & $\begin{array}{l}15 \\
15\end{array}$ & $\begin{array}{l}14 \\
14\end{array}$ & $\begin{array}{l}35 \\
35\end{array}$ & $\begin{array}{l}64 \\
64\end{array}$ & $\begin{array}{l}\text { No significance } \\
\qquad \mathrm{p}=1\end{array}$ \\
\hline
\end{tabular}

Individual $^{\star}=$ Individual judgment 
The correlation of scoring between the physicians and the radiologists by Spearman rank correlation coefficient and the agreement of grouping by Cohen's kappa coefficient analysis are shown in Table 6. The correlation and the agreement for the same group of 64 head CTs were moderate and fair when "individual judgment" was used, but were very strong and moderate when the ACR AC was used. The correlation and the agreement for chest CT and abdominal CT using "individual judgment" were very poor.

Table 6. The correlation of scoring and the agreement of grouping of CT requests between the physicians and the radiologists by using "individual judgment" and the "ACR AC".

\begin{tabular}{|c|c|c|c|c|c|c|c|c|}
\hline \multirow[t]{2}{*}{ CT area } & \multirow{2}{*}{$\begin{array}{l}\text { Scoring } \\
\text { method }\end{array}$} & \multirow[t]{2}{*}{ Number } & \multicolumn{3}{|c|}{ Inter-rater correlation of scoring } & \multicolumn{3}{|c|}{ Inter-rater agreement of grouping } \\
\hline & & & Level & $\begin{array}{l}\text { Spearman } \\
\text { correlation }\end{array}$ & p-value & Level & $\begin{array}{c}\text { Kappa } \\
\text { agreement }\end{array}$ & p-value \\
\hline \multirow[t]{3}{*}{ Head } & Individual $^{*}$ & 100 & Moderate & 0.549 & $<0.0001$ & Poor & 0.179 & 0.007 \\
\hline & Individual $^{\star *}$ & 64 & Moderate & 0.653 & $<0.0001$ & Fair & 0.291 & 0.001 \\
\hline & ACR AC & 64 & $\begin{array}{c}\text { Very } \\
\text { strong }\end{array}$ & 0.857 & $<0.0001$ & Moderate & 0.565 & $<0.0001$ \\
\hline Chest & Individual $^{*}$ & 44 & Weak & 0.211 & 0.17 & N/A & $\mathrm{N} / \mathrm{A}$ & N/A \\
\hline Abdomen & Individual $^{\star}$ & 56 & $\begin{array}{l}\text { Very } \\
\text { weak }\end{array}$ & 0.172 & 0.205 & No & -0.69 & 0.497 \\
\hline
\end{tabular}

Individual $^{\star}=$ Individual judgment

Individual $^{* \star}=$ Individual judgment for the requests that met the specific clinical conditions of the ACR AC

$\mathrm{N} / \mathrm{A}=$ Not assessed. No statistics were computed because the score group by the physicians was a constant for chest CT. 


\section{Discussion}

This study was conducted in a university hospital that had pediatric subspecialties. In the year 2012 with limited MR capacity (i.e., 2 MR machines for 1325bed hospital and 1.4 million OPD visits per year), most of the MRI slots were reserved for studies that CT could not confidently give important information about. Besides, there was a shortage of anesthesiologists. The waiting time for pediatric MRI was quite long, particularly for the ones that need sedation; thus, many pediatric patients had to undergo CT instead.

The number of pediatric CTs in 2012 was 811 examinations, and nearly $80 \%$ of them were head CTs, chest CTs, and abdominal CTs, with the ratio of the head CT to the body CT around 1:0.9. Therefore, the authors studied the equal numbers of head CT and body CT to represent pediatric CT in the hospital.

From 200 CT requests, the radiologists suggested 52\% of head CTs and 64\% of abdominal CTs could have been replaced by MRI if available, while the physicians suggested a much lower the number, i.e., $27 \%$ of head CT and $3 \%$ of abdominal CT for MR preference. This information shows the demand for more pediatric MR capacity in the hospital. It also revealed a remarkable difference in the opinions on appropriateness between physicians and radiologists. Two examples of one head CTs and one abdominal CTs that the physicians considered appropriate, but radiologist suggested MR were - a teenage boy with Hodgkin disease developed the first episode of generalized tonic clonic seizure 3 weeks after chemotherapy, and the indication for urgent imaging was to rule out CNS lymphoma or posterior reversible encephalopathy syndrome, and - the 9th follow-up imaging of immature teratoma after treatment for a 12-year-old girl.

A previous study from Olkarinen et al in 2009 [14] reported 36\% of head CTs and $37 \%$ of abdominal CTs in patients under 35 years old were unjustified and most of these could have been replaced by MRI, based on the guideline recommended by the European Commission. The study of appropriateness of outpatient adult CTs referred from primary care clinics by Lehnert et al in 
2010 [15] revealed $65 \%$ of head CTs and $18 \%$ of abdomen/pelvis CTs were not considered appropriate according to proprietary evidence-based appropriateness criteria used by a national RBM program. Both studies were from the radiologists' opinions.

The score of CT appropriateness by individual judgment was based on the knowledge and experience of each specialist, the hospital resources, and the healthcare coverage. From the long waiting time of MRI in the authors' hospitals, both physicians and radiologists agreed that most of the 200 CT requests were appropriate. The number of inappropriateness was $2.5 \%$ from the opinion of the physicians and $17 \%$ from the radiologists. Most of the inappropriate requests considered by the radiologists were from head CT with clinical conditions of seizure, headache, and follow-up of the tumor which were elective cases and should have MRI.

From the subgroup consisting of 64 brain CTs that had been scored for appropriateness by both "individual judgment" and by the ACR AC, there was a better inter-rater correlation of scoring and a better inter-rater agreement of grouping when using the ACR AC. This reflected the usefulness of the guideline in making similar judgment in clinical practice. This finding also correlated with previous meta-analyses that the clinical practice can be improved by providing accurate medical guidelines [16]. However, many clinical problems were not addressed in the ACR AC [17], as shown in our study in which 96 from 100 pediatric body CTs did not fit in the criteria. With "individual judgment", even the appropriateness scores of chest CTs and abdominal CT were higher than for head $\mathrm{CTs}$, the inter-rater correlation and the inter-rater agreement were poorer.

In this study, three criteria were chosen to determine inappropriate CT requests. The first criteria, "imaging modality of choice", was rather ideal, regardless of hospital limitations. The second criteria, "individual judgment" allowed flexibility of judgment in the practice with limited resources, but it could easily be biased. The third criteria, the ACR AC, was evidence-based, regularly updated, and easily accessible, but not including many clinical conditions. Despite using the same criteria, the physicians and the radiologists had certain different opinions 
in identifying inappropriate CT requests. In the cases that CT and MRI might provide the same important information, the physicians preferred CT as the modality of choice while the radiologists preferred MRI. From the physicians' viewpoint, CT quickly and noninvasively provided important information that they could treat their patients early, and MRI should be for the patients whose diseases were not easily detected by CTs, because the study took much longer time and was relatively expensive which might not be affordable. From the radiologists' viewpoint, MRI, most of the time, provided more information, particularly, in neurology and abdomen, and without radiation.

A round-table discussion with evidence-based information in which their opinions could be tuned in the same way might be a solution. Any request doubtful of appropriateness in terms of modality of choice should not be proceeded unless there is a thorough communication and a proper discussion. It is important to improve the imaging facilities and the system to get to a better situation to provide a safe imaging service to the patients.

This study was a retrospective review, therefore having a limitation of data collection. The reason for a CT request might not be completely written down, such as the waiting time for MRI or the parent's affordability for the cost of MRI, which would affect the scoring of appropriateness. The second limitation was the determination of appropriateness by using the evidence-base guidelines. The ACR AC in 2012 was very good; however, the criteria covered only $34 \%$ of the CT requests in this study. The third limitation was from a small sample size with the analysis of data in the subgroups.

\section{Conclusion}

The number of inappropriate CT requests in the opinion of the physicians was much less than the radiologists' opinions. Although the same guideline was adopted, there were a ten-percent disagreement on the appropriateness of pediatric CT requests between them. The main difference was not from no indication for imaging but from the selected modality of imaging. The radiologists suggested MRI as modality of choice in much higher number than the physicians. 


\section{References}

1. Brody AS, Frush DP, Huda W, Brent RL RL; American Academy of Pediatrics Section on Radiology. Radiation risk to children from computed tomography. Pediatrics 2007;120:677-82.

2. Krille L, Dreger S, Schindel R, Albrecht T, Asmussen M, Barkhausen J, et al. Risk of cancer incidence before the age of 15 years after exposure to ionising radiation from computed tomography: results from a German cohort study. Radiat Environ Biophys 2015;54:1-12.

3. Brenner D, Elliston C, Hall E, Berdon W. Estimated risks of radiation-induced fatal cancer from pediatric CT. AJR Am J Roentgenol 2001;176:289-96.

4. Chodick G, Ronckers CM, Shalev V, Ron E. Excess lifetime cancer mortality risk attributable to radiation exposure from computed tomography examinations in children. Isr Med Assoc J 2007;9:584-7.

5. Pearce MS, Salotti JA, Little MP, McHugh K, Lee C, Kim KP, et al. Radiation exposure from CT scans in childhood and subsequent risk of leukaemia and brain tumours: a retrospective cohort study. Lancet 2012; 380:499-505.

6. Dovales AC, da Rosa LA, Kesminiene A, Pearce MS, Veiga LH. Patterns and trends of computed tomography usage in outpatients of the Brazilian public healthcare system, 2001-2011. J Radiol Prot 2016;36:547-60.

7. Pearce MS, Salotti JA, McHugh K, Metcalf W, Kim KP, Craft AW, et al. CT scans in young people in Northern England: trends and patterns 1993-2002. Pediatr Radiol 2011;41:832-8.

8. Broder J, Fordham LA, Warshauer DM. Increasing utilization of computed tomography in the pediatric emergency department, 2000-2006. Emerg Radiol 2007;14:227-32. 
9. Prabhakar AM, Misono AS, Hemingway J, Hughes DR, Duszak R Jr. Medicare Utilization of CT angiography from 2001 through 2014: continued growth by radiologists. J Vasc Interv Radiol 2016;27:1554-60.

10. Thomas KE. CT utilization--trends and developments beyond the United States' borders. Pediatr Radiol 2011;41 Suppl 2:562-6.

11. European Commission. Radiation protection 118: referral guidelines for imaging [Internet]. [cited 2017 May 9] Available from: https://health. gov.mt/en/forms/Documents/radiation_protection.pdf.

12. American College of Radiology. ACR Appropriateness Criteria [Internet]. [cited 2019 July 14]. Available from: https://www.acr.org/Clinical-Resources/ ACR-Appropriateness-Criteria.

13. Cascade PN, Webster EW, Kazerooni EA. Ineffective use of radiology: the hidden cost. AJR Am J Roentgenol 1998;170:561-4.

14. Oikarinen H, Merilainen S, Paakko E, Karttunen A, Nieminen MT, Tervonen O. Unjustified CT examinations in young patients. Eur Radiol 2009;19:11615.

15. Lehnert BE, Bree RL. Analysis of appropriateness of outpatient CT and MRI referred from primary care clinics at an academic medical center: how critical is the need for improved decision support? J Am Coll Radiol 2010;7:192-7.

16. Grimshaw JM, Russell IT. Effect of clinical guidelines on medical practice: a systematic review of rigorous evaluations. Lancet 1993;342:1317-22.

17. Bautista AB, Burgos A, Nickel BJ, Yoon JJ, Tilara AA, Amorosa JK, et al. Do clinicians use the American College of Radiology Appropriateness criteria in the management of their patients? AJR Am J Roentgenol 2009;192:1581-5. 